\title{
Application Analysis of "Flipped Classroom" Model in University Computer Teaching
}

\author{
Guanghua $\mathrm{Yu}^{1^{*}}$, Lunbin $\mathrm{Li}^{1}$, Kuiling $\mathrm{Xia}^{1}$ \\ ${ }^{1}$ Computer Science and Information Engineering, Heihe University, Heihe 164300, China
}

Keywords: Undergraduate education; Computer teaching; Flipped classroom model

\begin{abstract}
Flipped classroom has become a teaching mode concerned by colleges and universities in China. How to apply flipped classroom in computer teaching and form a complete connection before and after class. Aiming at this problem, this paper gives the application method of flipped classroom teaching mode in computer teaching by referring to the successful cases at home and abroad and combining with teaching practice. And a brief analysis of the flipped classroom in the form of micro class, it realizes knowledge transfer, knowledge construction and internalization, and provides reference for college teaching model.
\end{abstract}

\section{Introduction}

In the context of the popularization of Internet technology and mobile terminals, the education field has also begun to reform teaching based on this status quo. Combining the characteristics of computer teaching and using the advantages of modern educational technology to realize the application of the flipping classroom teaching mode is conducive to the realization of students' practical operation ability, which is one of the effective ways to cultivate students' computer literacy. The application of flipping classroom teaching mode is essentially the sharing of educational resources in the network age, and also the innovation of teaching methods under the influence of modern educational concepts. This kind of teaching mode has gradually break the traditional teaching models, and the subjectivity of students has been highlighted and laying a foundation for the comprehensive development of students.

\section{The Definition of the "Flipped Classroom" Model}

The flipping classroom mode is also called the reverse classroom mode ${ }^{[1] .}$ Under this teaching mode, teachers need to break the limitations of traditional teaching mode in teaching time and space, give full play to the advantages of personalized teaching, optimize the learning experience of students, and promote students' Self-learning ability is improved. In the context of flipping classrooms, teachers often need to apply micro-videos and introduce teaching cases to guide students to learn independently. Classroom teaching resources are no longer limited to teachers' personal knowledge base and textbook content, but turn the application vision of teaching resources to a larger space. In daily education and teaching activities, teachers will use the guidance method to guide students to learn independently, but they also actively participate in it, answering and dispelling doubts for students. Under such a teaching atmosphere, teachers have completed the role transformation and become the guidance of classroom teaching activities.

\section{Application of "Flipped Classroom" Model in University Computer Teaching}

In order to improve the independent learning ability and computer operation ability of college students, the computer teaching in colleges and universities has begun to apply the flipping classroom teaching mode. The author will combine the teaching experience of the following to analyze the application of the flipping classroom teaching mode in college computer teaching and researching.

\subsection{Teaching arrangement deployment}

In the flipping classroom teaching mode, teachers need to do a good job in preparation before class, including the preparation of the content of the guide and the presets of the classroom questions. Teachers need to combine specific teaching content, select case teaching content that meets professional needs, and 
build a platform that can meet students' communication and questioning, provide students with corresponding learning interaction and curriculum evaluation opportunities, and effectively realize the combination of teaching arrangement virtualization and reality ${ }^{[2]}$. Applying this teaching mode, not only the students' enthusiasm for learning is improved, but also the teachers' classroom teaching pressure is reduced, which is conducive to the realization of the goals of the university and the cultivation of students' independent learning ability.

\subsection{Teaching content}

\subsubsection{Open teaching content}

Under the classroom teaching mode, computer teaching should be open, meet the individualized learning needs of students, and promote the development of students' innovative ability. In the process of university computer teaching, the teacher design teaching content must be combined with professional characteristics. If the professional knowledge of the design is strong, the professional teachers of the college can be invited to participate in the course production. Computer teaching is not only limited to the classroom, but also can provide knowledge lectures or establish a network learning resource sharing platform. In addition, combined with the employment needs of college students, we can establish a school-enterprise cooperation curriculum reform mechanism, share the excellent videos of students participating in the enterprise, and promote the organic connection between the university curriculum teaching and the enterprise talent demand.

\subsubsection{Modular teaching content}

In the context of flipping classroom teaching, teachers should ensure the rationalization and modularization of classroom teaching content in the process of designing and arranging teaching content. Through the module teaching to enhance the pertinence of knowledge learning, to facilitate students to learn and remember, students can choose the corresponding knowledge content based on their knowledge and ability level. For example, in the computer course teaching, we can divide it into computer basic knowledge, network basic knowledge, Word typesetting, Excel data statistics, PowerPoint slide production and other modules. Students can choose the module learning order according to their own characteristics and foundation.

\subsubsection{Teaching content visualization}

The visualization of flipping classroom teaching content is generally achieved by using micro video, but the teacher's pre-class preparation workload will be larger than the traditional teaching mode. At the same time, we must ensure the visibility of the video, and ensure that the video is short in duration and content. Specific requirements: clear content, clear knowledge points, and operability. After the video is over, the knowledge points are tested to check the student's learning effect. For example, in the section of "Snowflake Drift" animation effect in PowerPoint, first teachers must focus on the principle of falling snow, and then expand the teaching, such as showing the effect of "raining" scenes, cultivating students' ability to give inferences, and promoting students' thinking divergence and Increased interest. Teachers need to upload videos during the pre-class preparation stage, so that students preview knowledge content before class and strengthen students' self-learning awareness.

\section{Design of "Flipped Classroom" Based on Micro Lesson}

\subsection{The role of micro class in "flipped classroom"}

As an important part of "flipped classroom", micro class directly determines the effect of knowledge transfer before class and affects the design of classroom teaching activities, thus affecting the final teaching effect. The micro class used for flipped classroom should not be a complete class, but should serve a link in the classroom or a collection of several teaching activities and be displayed through the online teaching platform. Micro-lessons include "micro-video", which is mainly explained and demonstrated by teachers, supplemented by learning resources such as courseware, cases and materials. "Homework exercise" is the main activity, online answering is the auxiliary, online testing, online survey 
and other independent learning activities learning feedback. The complete micro-lesson in the classroom should include courseware, cases, learning materials, supplemented by after-class learning feedback.

The selection of micro-course content must include the analysis and extraction of teaching objectives, teaching objects and teaching contents, and it is necessary to make teaching video and collect online teaching resources according to the actual teaching needs. In addition, it is also necessary to set up learning feedback such as homework exercises and online answering questions, so as to provide an information-based learning environment and timely understand students' learning conditions and problems. The length and difficulty of micro-class learning should depend on the content of classroom teaching. The length of micro-video should not exceed 15 minutes, and the time to complete the whole micro-lesson should be controlled at about 30 minutes. The process of classroom inversion is obtained through relevant studies at home and abroad, as shown in fig 1.

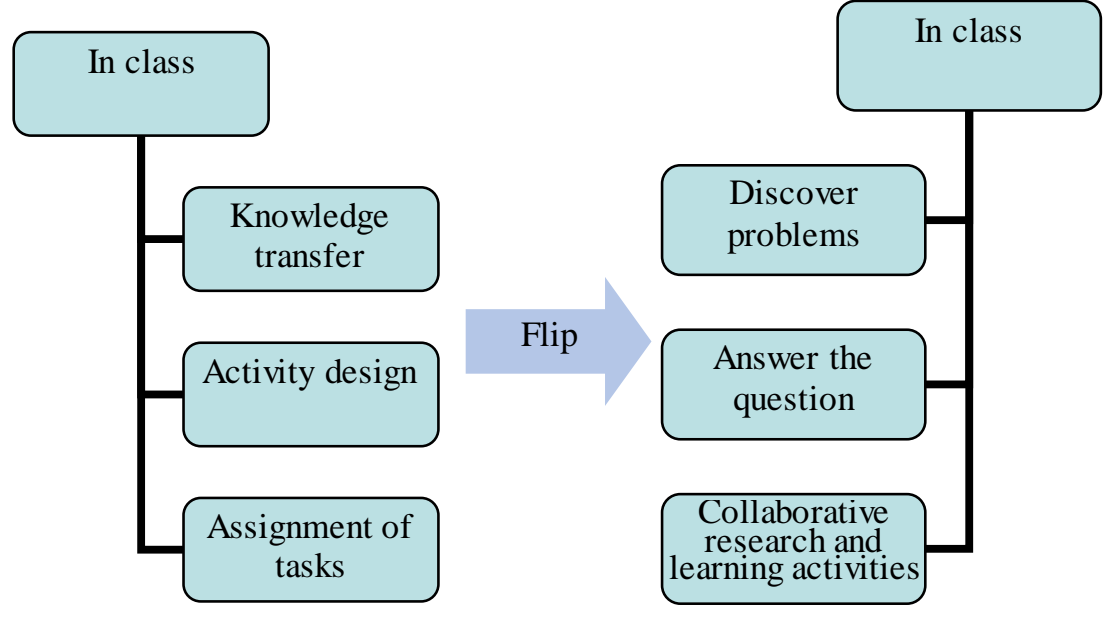

Fig. 1 "flip” diagram of teaching structure

\subsection{Design of micro class in "flipped classroom"}

Pre-class preparation stage: Teachers according to the needs of teaching arrangements, combing the content of teaching units for micro-class production. Pre-class delivery phase: students in the prescribed time by watching micro-video, participate in online questions, discussions and other links to complete the tasks set by teachers, to achieve the transfer of knowledge or skills. In-class stage: the teacher solves the problems collected by the teacher in the pre-class transfer stage, and organizes the exploratory class or discussion class according to the types of problems. After answering the questions, the teacher sets up typical tasks, and students can independently explore or form a team to learn according to the difficulty level of tasks. The teacher may observe the students' operation or communicate and discuss with the students nearby. Consolidation stage after class: Teachers evaluate students according to their accomplishments and display excellent learning works on the network teaching platform. Teachers can also collect teaching content related to the expansion of learning resources, which can be set expansion tasks. Students who are able to learn can challenge the expansion tasks to consolidate and expand their knowledge or skills.

Taking "Flash Production" as an example to introduce the specific application of micro-courses in computer-based teaching. Flash production is an important module of college computer teaching content. This part of knowledge learning is actually difficult for many college students. If teachers do not rely on any technical means in the process of organizing teaching activities, it is difficult to complete this part of content teaching within 2 class hours. Therefore, in the teaching process, the author applies micro-curricular production video resources to provide students with independent learning opportunities. Flash production includes simple animation production, use of component scenes, use of timeline, and tween animation. In order to arouse the students' learning enthusiasm, the author applied a series of micro-course videos such as "Bending the Moon to Change the Moon" and "Bounce Ball" to show Flash animation. The students' enthusiasm for learning was significantly improved by the wonderful video. 


\section{Conclusion}

Under the support of modern science and technology, the application of flipping classroom teaching mode has gradually become popular. Combining teaching practice to provide students with independent learning opportunities and satisfying students' individualized learning needs is an important purpose of flipping classroom teaching mode application. Colleges and universities are the main positions for the cultivation of computer professionals. Based on the application demand of flipped classroom teaching mode, applying it in college computer teaching activities can provide assistance for the improvement of the teaching quality of computer teaching courses. The above viewpoints hope to provide reference for computer teaching in colleges and universities.

\section{Acknowledgment}

Fund project: Philosophy and social science research program project of Heilongjiang province(16EDC04)

\section{Reference}

[1]. Xiaoli Cai, Shunyu Chen, Applied research of flipped classroom in university computer information technology class[J].FuJian Computer,2013,11(29):257-259

[2]. YiChen, Chengling Zhao, Teaching design and application research based on flipped classroom model [J] Modern Educational Technology, 2014, 32(24):249-254.

[3]. Jin Yan, Practical research on flipped classroom teaching model based on micro class--Take computer application foundation as an example[J]. Journal of Vocational Education. 2014, 12(23):255-258.

[4]. luo Zhiqing, Ma Jinqiao, Jiang Yanli, Discussion on the application of microlecture in college computer teaching[J]. The Chinese youth, 2015,12(21):176-177 